\section{CONDUCTIVE MATERIAL PROPERTIES FOR FDM} ADDITIVE MANUFACTURING

JURAJ BENIAK, PETER KRIZAN, MILOS MATUS

Slovak University of Technology in Bratislava, Faculty of Mechanical Engineering, Bratislava, Slovak Republic

DOI : 10.17973/MMSJ.2020_03_2019135

juraj.beniak@stuba.sk

Additive Manufacturing technologies use different materials for producing of design parts. Most used technologies of additive manufacturing are Fused deposition modelling (FDM) which use plastic wires for deposition of parts layers. There are also others technologies which use for example resins, paper, plastic powder but also steel and producing of parts from metal powder. Also in plastic materials is wide range of polymers which are suitable for FDM technology. Conventional materials are ABS, PLA, Nylon, PETG and others polymers. There are also special composites where the base is conventional polymer and particles of other solid material as glass, metal, wood which give to produced parts specific properties or appearance. Very specific material is conductive material which can conduct the electrical current. Presented paper deals with using of conductive PLA filaments for part producing. There are described results from scientific experiments which are prepared by standard methods and evaluated by statistical methods. Measured are material properties and electrical resistance.

KEYWORDS

Conductive material, Additive manufacturing, 3D printing, Fused Deposition Modelling, Tensile strength

\section{INTRODUCTION}

Additive manufacturing is very diverse, utilizing various technologies of material application and production of parts as well as a wide range of materials. We see great progress and development in the area of materials for additive production. It is possible to explore new types of materials that are adapted to additive technologies and reflect the needs of the current market. New types of materials are also being developed, especially for use in additive technologies and in the production of special parts for special applications. These are materials that would not have arisen if the area of additive production had not developed.

The following article will be devoted to FDM (Fused Deposition Modeling) technology for additive manufacturing. This is the most widespread technology, mainly because of the economical expediency and undemandingness of the technology itself, as well as the availability and costeffectiveness of used materials.

The technology uses pure-based thermoplastic polymers and copolymers as a basic matrix material, as we know it from conventional engineering in areas where plastics such as the automotive industry are used. These include ABS (Acrylonitrile butadiene styrene) plastics, Nylon, PET (Polyethylene Terephthalate) material, Polypropylene (PP) plastic and others [Beniak 2014]. As a further level of plastics for the FDM area of additive manufacturing, various composite materials may be comprised of the base plastics mentioned above. Composite materials always contain a certain percentage of additional solid materials of different structure and size. For example, wood composite materials are based on a PLA base material and in some cases contain up to $60 \%$ wood particles. Similarly, other composite materials use PLA as a base because they are easy to use, simply make parts using FDM technology, and have the advantage that they do not have the disadvantages of other materials such as deformation in 3D printing or after printing when the component cools down, thereby shortening the applied fibers and thereby deforming the entire component. Solid materials used in composites include, for example, carbon strings, ceramic particles, various types of stones, copper, bronze, brass and others, in addition to wood. The role of the additional solid particles is to improve the properties of the material at various levels. For example, the use of carbon fibers is a reduction in weight and an increase in strength of the parts produced [Beniak 2015]. For other particles, it may be a design aspect where the workpiece gets the look and feel of being made of wood, ceramics, bronze, brass, in between and the like. The included particles may also improve the properties of the base material.

\section{MATERIAL AND METHODS (EXPERIMENT PREPARATION)}

For experiments within this presented paper is used special material conductive PLA filament with $1.75 \mathrm{~mm}$ as diameter and experimented as this thermoplastic has a special quality to conduct electricity. The special material conductive PLA is a product of 4043D PLA, is a dispersing agent and contains carbon black as the filler materials which is conductive and responsible to lead electricity [Proto-Plant 2018]. The presence of carbon black in the blend makes it to be a conductive filament.

The important ingredients in conductive PLA filament are polylactide resin, carbon black and polymer. The weight percentage of polylactide resin, carbon black and polymer are found to be $>65 \%,<21.43 \%$ and $<12.7 \%$ respectively. The volume resistivity of conductive PLA filament is found to be 15 ohm-cm ( 0.15 ohm-m or $15 \times 10-2 \Omega-m)$ which has been claimed by the manufacturer [Proto-Pasta 2018]. Carbon black contains fine particles consisting mainly of carbon. Carbon black is widely used in various applications from black coloring pigment of newspaper inks to electric conductive agent of hightechnology materials [Kwok 2017], [Gnanasekaran 2017].

Carbon black is composed of fine particles consisting mainly of carbon. Various features of carbon black are controlled in production by partially combusting oil or gases. Carbon black is widely used in various applications from black coloring pigment of newspaper inks to electric conductive agent of hightechnology materials [O'Neil 2019].

Carbon black is produced with the thermal decomposition method or the partial combustion method using hydrocarbons such as oil or natural gas as raw material. The characteristics of carbon black vary depending on manufacturing process, and therefore carbon black is classified by manufacturing process. Carbon black produced with the furnace process, which is the most commonly used method now, is called "furnace black," distinguishing it from carbon black, which is manufactured with other processes.

Carbon black also provides stable resistance, and therefore is used as electronic equipment related material in various display components, magnetic recording materials, and OA rolls. Furthermore, Mitsubishi Chemical has been developing carbon black with various combined functions for special applications. 

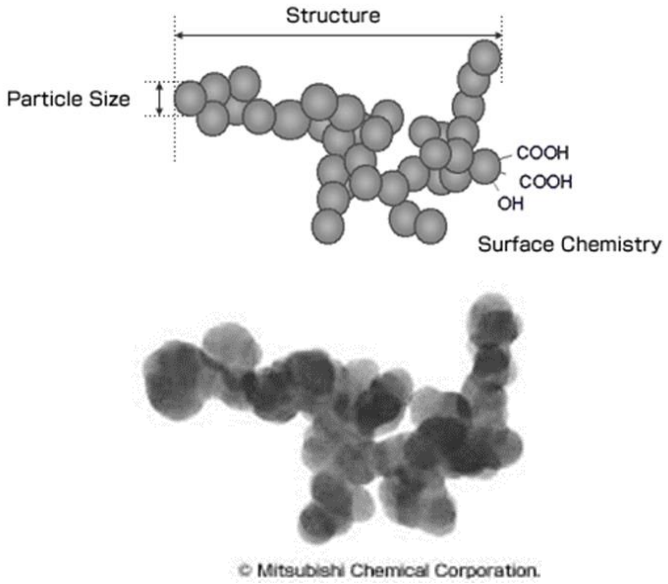

Figure 1. Structure and Electron microscope image of carbon black [Mitsubishi 2006]

Observing carbon black particles under the electron microscope shows that they have a complicated structure, with some spheric particles being fused together. The size of spheric particles is called "particle size," and the size of the particle chain is called "structure." Various functional groups such as the hydroxyl or carboxyl group are found in the surface of carbon black, and their amount or composition is called "surface chemistry."

These three - "particle size," "structure," and "surface chemistry" - are the basic properties of carbon black, and together are called the three main characteristics. The three main properties have a large effect on practical properties such as blackness and dispersibility when they are mixed with inks, paints, or resins [Mitsubishi 2006].

Particle Size - The diameter of spheric particles is the fundamental property which largely affects blackness and dispersibility when carbon black is mixed with resins or other vehicles. In general, the smaller the particle size is, the higher the blackness of carbon black becomes.Dispersion, however, becomes difficult due to an increase in coagulation force.

Structure - Like particle size, the size of the structure also affects the blackness and dispersibility of carbon black. Generally, the increase of structure size improves dispersibility but lowers blackness. Carbon black with a larger structure in particular shows an excellent conductive property.

Surface Chemistry - Various functional groups exist on carbon black's surface. The affinity of carbon black with inks or paint varnishes changes depending on the type and amount of the functional groups.

Carbon black, with a large amount of hydroxyl group given with oxidation treatment, has a greatly enhanced affinity to print inks or varnishes, showing an excellent dispersibility.

There is known from ohm's law, the resistance of an object could be calculated easily by using the relation for resistance

$R=\frac{\rho^{-l}}{A}(\Omega)$

where resistivity $(\rho)$ is constant for the material and the value equals to $0.15 \Omega \mathrm{m}$ which is claimed by the manufacturer. We all know that the resistance of material increases by increasing the length or decreasing the area. Also, to understand the relation for the resistance of the material and temperature is given by the relation [Nick 2004], [Elert 2019],

$\frac{\Delta \mathrm{R}}{R_{\mathrm{n}}}=\propto \Delta T$
$R=R_{0}\left[1+\infty\left(T-T_{0}\right)\right]$

where:

$\mathrm{R}_{0}=$ Resistance value at room temperature $(\Omega)$

$\mathrm{T}_{0}=$ Room temperature $\left({ }^{\circ} \mathrm{C}\right)$

$\mathrm{T}=$ Elevated temperature $\left({ }^{\circ} \mathrm{C}\right)$

$\alpha=$ thermal expansion coefficient $\left({ }^{\circ} \mathrm{C}^{-1}\right)$

To understand the relation between nozzle temperature and length of the specimen, the samples were printed with two extreme nozzle temperature for different lengths. It is very interesting that how the nozzle temperature of the 3D printer could affect the resistance of the printed sample. To test so, the samples were printed with two different nozzle temperatures. In-order to understand the relation even further, the sample's resistance was measured at $25^{\circ} \mathrm{C}$ (room temperature) and $80^{\circ} \mathrm{C}$ (elevated temperature).

The carbon black (an electrically conductive filler material) diffused into a polymer matrix such as Polylactic acid produces a composite material which was studied by several authors. Hence these composite materials show a linearly keen increase in electrical resistance at different elevated temperatures [Hasnaoui 2011].

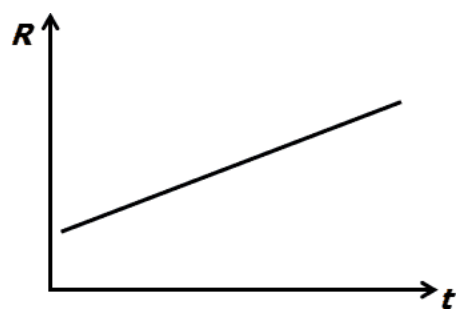

Figure 2. Relation between electrical resistance and temperature [Hasnaoui 2011]

Electrical resistance for samples were measured using the digital multimeter PU510 with $\pm 0.5 \%$. The measurements were taken both at ambient temperature $\left(25^{\circ} \mathrm{C}\right)$ and elevated temperature $\left(80^{\circ} \mathrm{C}\right)$. Each sample should be measured at least 5 times to reduce inaccuracy in results. From the Figure 23 , the plotted line shows a steady and linear increase for different resistance and temperature. It happens only if a material is said to be a good conductor of electricity. From this it can be that predicted even for our experiment it should follow a similar pattern as our special material also said to be conductive.

\subsection{Stensile strength experiment}

When the designers think over the appropriate selection of suitable material, they need to know what are the material properties and strength of used material. Conductive filament can be used to produce specific parts where is required conductivity, mostly for low voltage applications.

For this purpose is designed the full factor experiment where are includes three factors (Table 1). As specimens are designed the CAD models of tensile strength samples (Figure 3), which are following the ISO standard for tensile strength testing. 

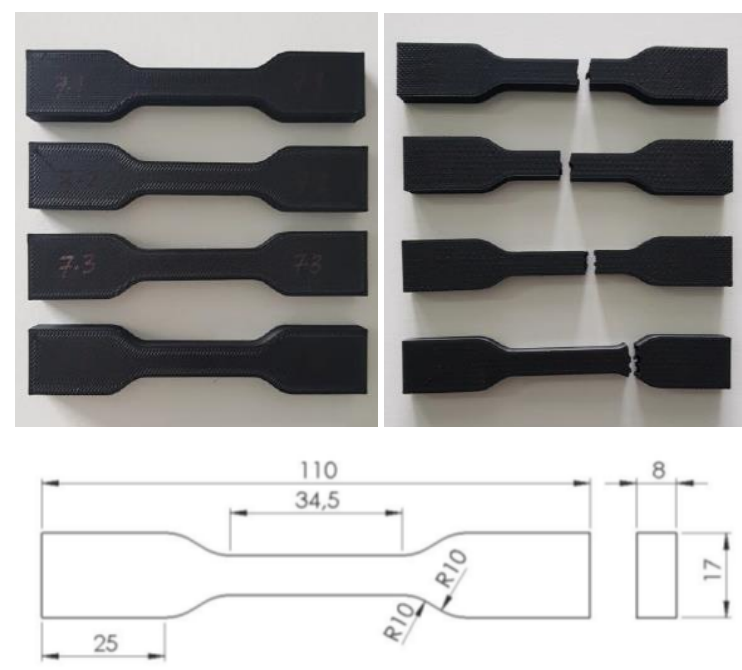

Figure 3. Specimens for tensile strength testing

For production of specimens and for full factor experiment are chosen three factors which are affecting the strength of produced parts. Volume of infill is mass of material inside of produced specimens. By previous experiments [Beniak 2014], we suppose also in this case that volume of material will have affect to measured tensile strength. Second factor is layer height, specified in two levels and the reason for choosing of this factor is the same. The last, third factor is infill type. We placed basic rectilinear structure and the second popular honeycomb. The purpose of this experiment is to specify what is the maximum tensile strength till break of specimen.

\begin{tabular}{|l|l|l|}
\hline Factor & Level 1 & Level $\mathbf{2}$ \\
\hline A - Infill Vol & $50 \%$ & $90 \%$ \\
\hline B - Layer height & $0,125 \mathrm{~mm}$ & $0,25 \mathrm{~mm}$ \\
\hline C - Infill Type & Rectilinear & Honeycomb \\
\hline
\end{tabular}

Table 1. Factors for design of experiment for tensile strength

The tensile strength measuring is made on Universal testing machine Inspekt Desk 5kNEach measuring is repeated 5 times, for accurate statistical evaluation.

\subsection{Conductive material resistance experiment}

The primary purpose of the use of conductive material is to apply to low-voltage circuits or components where they need to conduct electrical current. For this it is necessary to know the electrical properties of used materials. The following section will describe the design of a full-factor experiment for measuring the material resistivity with selected conditions and factors. As shown in Table 2, there are used two factors. Factor $A$ is printing temperature or the set value of nozzle temperature during production. This factor is on two levels, $190^{\circ} \mathrm{C}$ and $220^{\circ} \mathrm{C}$. This is the range of temperatures specified by producer of PLA conductive filament.

The second factor is length of specimens for measuring. To obtain as much data as possible we decided for range from 10 to $100 \mathrm{~mm}$, with step $10 \mathrm{~mm}$. So at all there is 10 levels of this factor.

\begin{tabular}{|l|c|c|c|c|}
\hline Factor & Level 1 & Level 2 & $\ldots . . .$. & Level 10 \\
\hline $\begin{array}{l}\text { A }- \text { Printing } \\
\begin{array}{l}\text { Temperature } \\
\hline \text { B - Length of } \\
\text { specimen }\end{array}\end{array}$ & $190^{\circ} \mathrm{C}$ & $220^{\circ} \mathrm{C}$ & - & - \\
\hline \hline
\end{tabular}

Table 2. Factors for design of experiment for resistivity

Specimens for measurement are shown on Figure 4. It is simple rod with square cross-section with dimension $2 \mathrm{~mm} \times 2 \mathrm{~mm}$. Length is given by experiment from $10 \mathrm{~mm}$ to $100 \mathrm{~mm}$.

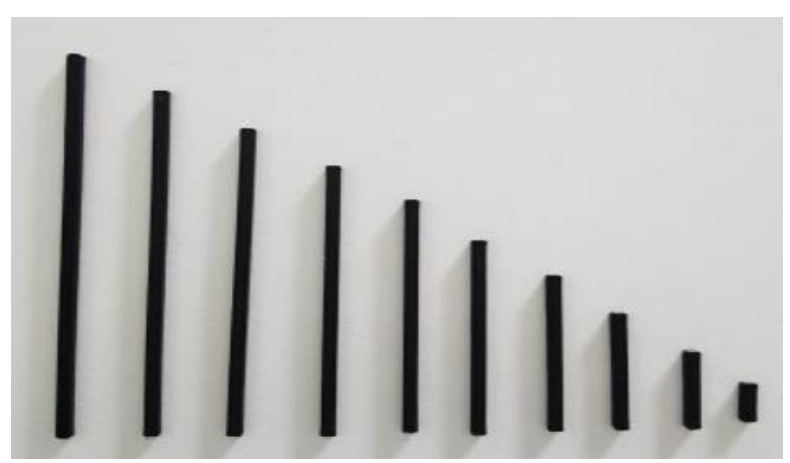

Figure 4. Specimens for resistance measurement

For measurement is used digital multimeter PU510 with accuracy $\pm 0.5 \%$. Each measuring is repeated 5 times, for accurate statistical evaluation.

\section{RESULTS AND DISCUSSION}

As described above, the whole measurement is divided to two parts. Measured values and their evaluation is prezented in following paragraphs.

\subsection{Stensile strength experiment}

Table 3 present measured values of tensile strength at break with prepared specimens. Each measuring is repeated 5 times for proper statistical evaluation. In the table are placed average values in each experiment setting.

\begin{tabular}{|c|c|c|c|c|}
\hline $\begin{array}{c}\text { Exp. } \\
\text { No. }\end{array}$ & A & B & C & $\begin{array}{c}\sigma_{m} \\
(\mathrm{MPa})\end{array}$ \\
\hline 1 & 1 & 1 & 1 & 12,83 \\
\hline 2 & 2 & 1 & 1 & 31,80 \\
\hline 3 & 1 & 2 & 1 & 18,66 \\
\hline 4 & 2 & 2 & 1 & 32,10 \\
\hline 5 & 1 & 1 & 2 & 17,03 \\
\hline 6 & 2 & 1 & 2 & 23,84 \\
\hline 7 & 1 & 2 & 2 & 18,55 \\
\hline 8 & 2 & 2 & 2 & 25,29 \\
\hline
\end{tabular}

Table 3. Measured values of tensile strength 
Highest measured value is $32,1 \mathrm{Mpa}$, with $90 \%$ infill volume, $0,25 \mathrm{~mm}$ layer height and Rectilinear infill type. Relative measured numbers are also print with $90 \%$ infill.

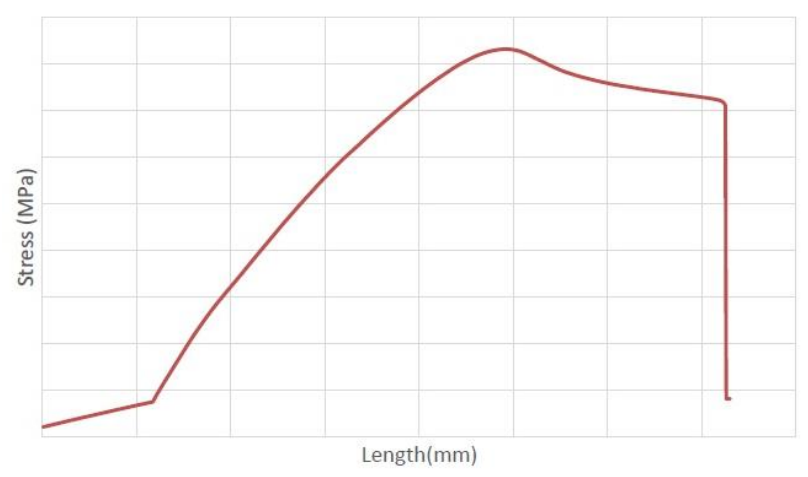

Figure 5. Diagram of tensile strength test

On the Figure 6 is shown the graphical representation of measured values for better illustration of outputs. There are easy to see the highest peaks.

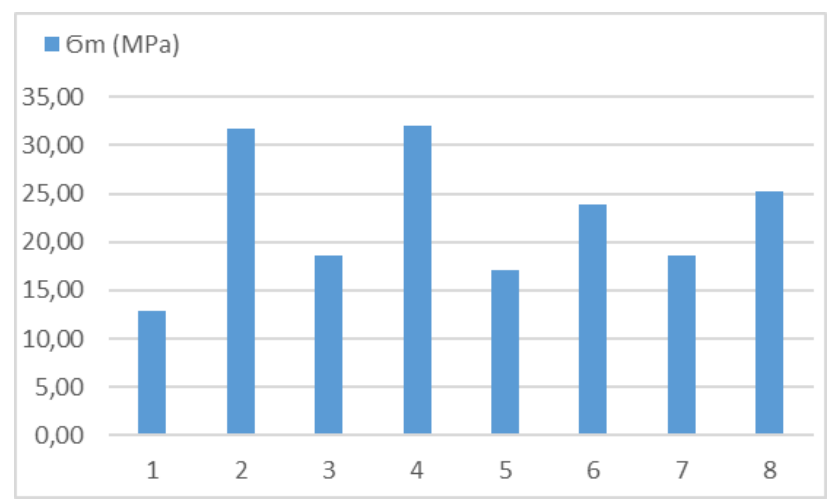

Figure 6. Representation of measured tensile strength values

By statistical evaluation is possible to specify also the most important and most significant factors, resulting from experimentally stated tensile strength average values. Final evaluation of factors are visible on Figure 7. In case of factor $A$ A1 means effect of $A$ factor with Level 1. A2 means effect of $A$ factor with Level 2. Difference between this values state how significant if this factor for final tensile strength. The same situation is also within of others two factors.

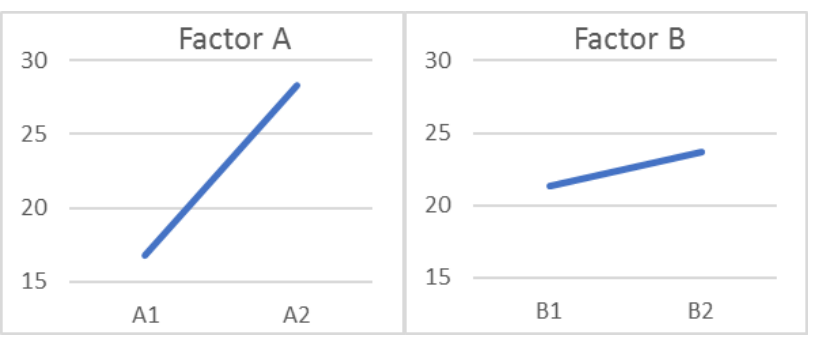

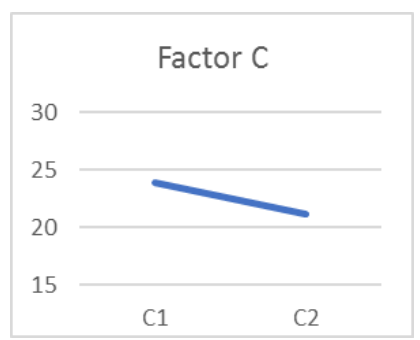

Figure 7. Significance of presented factors on their levels for tensile strength testing

This means that the factor A have the biggest influence to tensile strength. The others two have some influence, but not so significant.

\subsection{Conductive material resistance experiment}

Measured values of resistance and the structure of experiment is shown in Table 4. For two different production temperatures $190^{\circ} \mathrm{C}$ and $220^{\circ} \mathrm{C}$ are produced specimens in the shape of long rod with lengths $10 \mathrm{~mm}, 20 \mathrm{~mm}, 30 \mathrm{~mm}, 40 \mathrm{~mm}, 50 \mathrm{~mm}, 60 \mathrm{~mm}$, $70 \mathrm{~mm}, 80 \mathrm{~mm}, 90 \mathrm{~mm}$ and $100 \mathrm{~mm}$ as is visible in Table 4. For each experiment are produced 5 samples and realized 5 measurements for better statistical evaluation. With increasing of lengths, the resistance also increase, what follows the Ohm law. The same situation is in case of both used nozzle temperatures.

\begin{tabular}{|c|c|c|c|}
\hline Exp.No. & $\begin{array}{l}\text { Length } \\
(\mathrm{mm})\end{array}$ & $\begin{array}{l}\text { Temperature } \\
\left({ }^{\circ} \mathrm{C}\right)\end{array}$ & $\begin{array}{c}\text { Resistance } \\
(\Omega)\end{array}$ \\
\hline 1 & 10 & 190 & 1,34 \\
\hline 2 & 10 & 190 & 1,72 \\
\hline 3 & 30 & 190 & 2,24 \\
\hline 4 & 40 & 190 & 2,46 \\
\hline 5 & 50 & 190 & 2,71 \\
\hline 6 & 60 & 190 & 3,08 \\
\hline 7 & 70 & 190 & 3,52 \\
\hline 8 & 80 & 190 & 3,83 \\
\hline 9 & 90 & 190 & 4,58 \\
\hline 10 & 100 & 190 & 4,82 \\
\hline 11 & 10 & 220 & 0,89 \\
\hline 12 & 10 & 220 & 1.20 \\
\hline 13 & 30 & 220 & 1,40 \\
\hline 14 & 40 & 220 & 1,75 \\
\hline 15 & 50 & 220 & 2,09 \\
\hline 16 & 60 & 220 & 2,37 \\
\hline 17 & 70 & 220 & 2,66 \\
\hline 18 & 80 & 220 & 2,97 \\
\hline 19 & 90 & 220 & 3,28 \\
\hline 20 & 100 & 220 & 3,62 \\
\hline
\end{tabular}

Table 4. Plan of experiment and measured values

Graphical visualisation of measured values is presented on Figure 8 and Figure 9. The graphs are divided by nozzle 
temperature. On top figure are experiments from 1 to 10 , with nozzle temperature $190^{\circ} \mathrm{C}$. On bottom figure are experiments from 11 to 20 with nozzle temperature $220^{\circ} \mathrm{C}$.

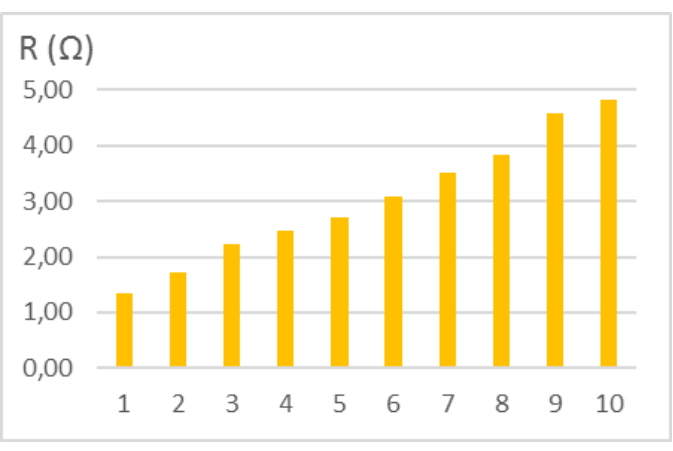

Figure 8. Representation of measured resistance values for experiments 1 to 10 for temperature $190^{\circ} \mathrm{C}$

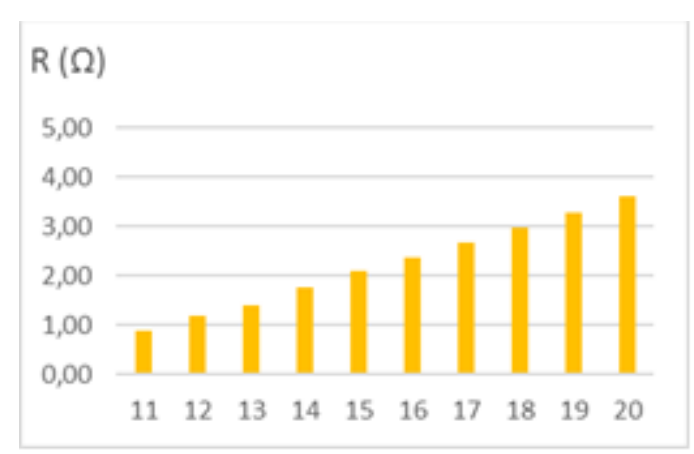

Figure 9. Representation of measured resistance values for experiments 11 to 20 for temperature $220^{\circ} \mathrm{C}$

Also in case of factors used for resistance measuring is possible to specify their significancy. There is possible to see that the temperature and also the length are significant and change of their values affect the final resistivity of produced specimens (Figure 10 and Figure 11).

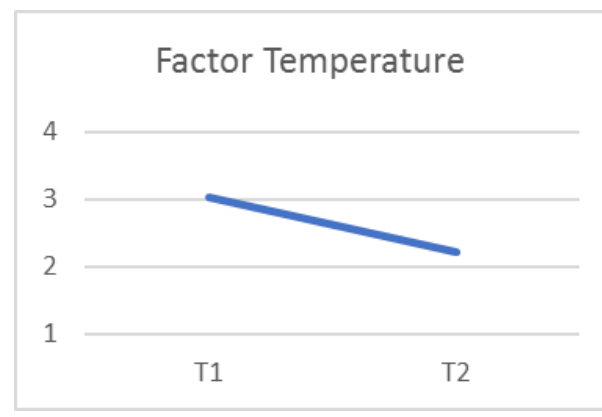

Figure 10. Significance of Temperature factor on its levels

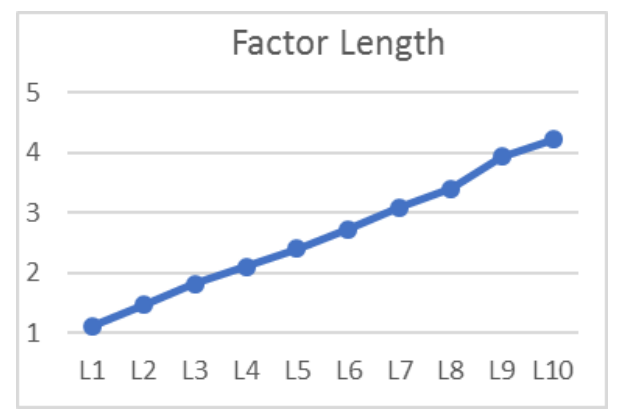

\section{CONCLUSIONS}

On the basis of realized experiments mentioned above cold be stated some conclusions. Experiments are focused to testing of conductive PLA material used for FDM Additive Manufacturing technology. The purpose of this experiments is to specify strength of produced samples and also important electrical properties of specimens. As stated in previous paragraphs, in case of tensile strength testing, there is most significant effect of infill volume, what have been acknowledged also on many previous scientific papers of author [Beniak 2015] and others researchers. This result is based also on known principles from mechanical engineering praxis. The second most significant factor is infill type. There is tested rectilinear and honeycomb infill. Based on measured values is possible to state that the rectilinear type is in this experiment more strength as honeycomb. Honeycomb is known as better structure, but it is more for compression load. Our specimens are loaded by tensile load. The last factor (layer height) is less significant as previous two. What is important also to know, and Why we did this measurements, to know what is the tensile strength. The highest value measured in our testing is $32 \mathrm{MPa}$, but this is just with $90 \%$ infill. So real of $100 \%$ infill specimen will be higher. Based on such measurement, the maximum tensile strength in break is $42 \mathrm{MPa}$.

For testing and experiments focused to resistivity of conductive material are stated following conclusions. Based on ohm law and realized experiments can be say that the relation between length of produced specimens and resistivity is linear. When taking into the account the temperature of nozzle during 3D printing, it is noticeable that with higher temperature $220^{\circ} \mathrm{C}$ the measured values of resistivity are much low. In one case, when we compare the measured values, it is about $30 \%$ difference. This is caused by structural change in the material structure.

Conductive PLA plastic filament is suitable for low voltage application and also the strength of material is comparable with conventional materials. The only disadvantage is relative high price of mentioned filaments.

\section{ACKNOWLEDGMENTS}

The research presented in this paper is an outcome of the project APVV-18-0527 "Development and Optimization of Additive Manufacturing Technology and Design of Device for Production of components with Optimized Strength and Production costs", funded by the Slovak Research and Development Agency.

\section{REFERENCES}

[Beniak 2014] Beniak, J., Križan, P., Matúš, M., Svatek, M., Ecological PLA plastic used for FDM rapid prototyping technology, 15th International Multidisciplinary Scientific Geoconference and EXPO, SGEM 2015; Albena; Bulgaria; 18 June 2015 through 24 June 2015, Volume 1, Issue 2, 2015, Pages 117-123, DOI: 10.5593/SGEM2015/B21/S7.016

[Beniak 2015] Beniak, J., Križan, P., Matúš, M., A comparison of the tensile strength of plastic parts produced by a fused deposition modeling device, (2015) Acta Polytechnica, 55 (6), pp. 359-365. DOI: 10.14311/AP.2015.55.0359

Figure 11. Significance of Length factor on its levels 
[Elert 2019] Elert, G., Electric Resistance, The Physics Hypertextbook, 2019

[Gnanasekaran 2017] Gnanasekaran, K., Heijmans, T., Bennekom, S., Woldhuis, H., Wijnia, S., With, G., Friedrich, H., 3D printing of CNT- and graphene-based conductive polymer nanocomposites by fused deposition modeling, Applied Materials Today, Volume 9, 2017, Pages 21-28, ISSN 2352-9407, https://doi.org/10.1016/i.apmt.2017.04.003.

[Hasnaoui 2011] Hasnaoui, M. EL, Graça, M. P. F. , Achour, M. E., Costa, L. C., Lahjomri, F., Outzourhit, A., Oueriagli, A., Electrical properties of carbon black/ copolymer composites above and below the melting temperature (2011), Journal of material and environmental science. 2011

[Kwok 2017] Kwok, S.,W., Goh, K.,H.,H., Tan, Z.,D., Tan, S.,T.,M., Electrically conductive filament for 3D-printed circuits and sensors, Applied Materials Today, 2017, Pages 167-175, ISSN 2352-9407, https://doi.org/10.1016/j.apmt.2017.07.001.

[Mitsubishi 2006] Mitsubishi Chemical, Three Main Properties of Carbon Black, 2006, [online] 10.11.2019, Available from: http://www.carbonblack.jp/en/cb/tokusei.html
[Nick 2004] Nick M. Quinn, Anita Kallepalli, Theodore F. Wiesner, Temperature Dependence of Electrical Resistivity and Thermal Conduc- tivity for a Gel Model of Nerve Tissue, , Journal of Undergraduate Research in Bioengineering, 4 (2), p $99-104,2004$

[O'Neil 2019] O'Neil, G.,D.,, Ahmed S., Halloran, K., Janusz, J.,N., Rodríguez, A., Rodríguez, I.,M.,T., Single-step fabrication of electrochemical flow cells utilizing multi-material 3D printing, Electrochemistry Communications, Volume 99, 2019, Pages 5660, ISSN 1388-2481,

[Proto-Pasta 2018] Proto-Pasta Conductive PLA Material Safety Data Sheet (2018), [online] 10.11.2019, Available from: https://www.proto-pasta.com/pages/documentation

[Proto-Plant 2018] Proto-Plant Makers of Protopasta, Conductive PLA [online], December 2018, [online] 10.11.2019, Available from: https://www.protopasta.com/pages/conductive-pla DOI: https://doi.org/10.1016/j.elecom.2018.12.006.

\section{CONTACTS:}

doc. Ing. Juraj Beniak, PhD.

doc. Ing. Peter Križan, PhD.

doc. Ing. Miloš Matus, PhD.

Slovak University of Technology in Bratislava

Faculty of Mechanical Engineering

Nam. Slobody 17, 81231 Bratislava, Slovak Republic

juraj.beniak@stuba.sk,www.sjf.stuba.sk

peter.krizan@stuba.sk, www.sjf.stuba.sk

milos.matus@stuba.sk,www.sjf.stuba.sk 